\title{
Tongue dysfunction screening: assessment protocol for prescribers
}

\author{
H. Gil ${ }^{1}$, N. Fougeront ${ }^{2}$ \\ 1 Maxillofacial physiotherapist \\ 2 Dental surgeon, Orofacial Functional Disorder Consultation, Odontology Dept, \\ Charles-Foix Hospital, Ivry-sur-Seine, France
}

\begin{abstract}
The tongue rehabilitation technique developed by the physiotherapist Maryvonne Fournier may be prescribed in several medical disciplines: dentistry, orthodontics, oral and maxillofacial surgery, ENT, pulmonology, pediatrics, neurology and geriatrics. Other health care providers, such as speech therapists and dental hygienists, have also taken an interest in the technique. The aim of this article is to present a simplified non-operator-dependent version of the tongue dysfunction assessment protocol implemented in maxillofacial physiotherapy, that can be used by practitioners in all fields.
\end{abstract}

\section{KEYWORDS}

Tongue habits, rehabilitation, exercise therapy, temporomandibular disorder, obstructive sleep apnea syndrome, Eustachian tube, malocclusion

\section{INTRODUCTION}

Forty-five years ago, in response to a request from $\mathrm{Pr}$ Jean Delaire, the physiotherapist Maryvonne Fournier developed a tongue rehabilitation method $^{9}$. Since then, other health-care professionals have taken an interest in the method, yet it remains little known. Tongue posture and function disorders show high prevalence, depending on age and pathology. Between the ages of 6 and 9 years, 30\% of children have immature swallowing ${ }^{39}$. According to Flechter et al. cited by Servière ${ }^{31}$, prevalence is $21 \%$ at 18 years and, according to Wehrlich, cited by Servière ${ }^{31}, 26.4 \%$ at 17.5 years. There is no consensus as to a normal age for tongue posture and function maturity. According to Fournier ${ }^{9}$, it would be 2 years (establishment of deciduous dentition); according to Chateau $^{8}, 3$ years (stable deciduous dentition); according to Woda and Fontennelle ${ }^{39}$, primary tongue posture and function is dysfunctional if it persists after 10 years (transition from stable mixed dentition to adolescent dentition: a period of occlusal instability with lateral sector (teeth 3, 4 and 5) change). These differences in prevalence and age-threshold for dysfunction may be related to patient recruitment, treatment practices and requirements, and/ or care providers: physiotherapists, speech 
therapists, orthodontists, pediatric dentists; they may also, however, be due to non-standardization of diagnostic criteria.

The aim of the present article is to specify diagnostic criteria. Persistent primary lingual function does not in itself spell disorder; when, however, the impact of the dyspraxia is patho- genic, detection is vital and urgent, to allow early correction. The present assessment protocol is intended for dentists, orthodontists, maxillofacial surgeons, ENT specialists, pulmonologists, pediatricians, neurologists and geriatricians. In all these specialties, complete maxillofacial rehabilitation can enhance treatment efficacy.

\section{INTEREST OF AN ASSESSMENT PROTOCOL FOR NON-PHYSIOTHERAPISTS}

Maxillofacial rehabilitation is not taught in all physiotherapy schools, and practitioners able to assess and rehabilitate the tongue are not always easy to find. The present protocol was therefore designed with prescribers in view, to detect tongue dysfunction and associated disorders. "Difficult" patients, with iterative consultation, are not rare; they may present orthodontic and/ or surgical recurrence ${ }^{30}$, temporomandibular disorder (TMD) pain (Table I) 18,19,20,29,31 (frequently associated with migraine or tension headache) $)^{15}$, respiratory disorder (oral respiration, rhonchopathy, obstructive sleep apnea syndrome (OSAS) 24,36 , and/or hearing loss due to Eustachian tube dysfunction ${ }^{37}$.
All these pathologies have one thing in common: tongue dysfunction. Most of these so-called "difficult" patients have another thing in common: they have already tried many other treatments and consulted many other therapists. To resolve the problem of this medical market-place which reduces the quality of health care and increases public health costs, prescribers need a means of knowing whether lingual rehabilitation should be undertaken or not, so as to avoid the many cases of recurrence. In terms of means, certain tongue dysfunctions can be treated simply by counseling, or by neuromuscular training using devices such as Bonnet's sleep tongue envelope ${ }^{5,6,23}$. Not all cases require specialized physiotherapy.

Table I: Prevalence of lingual dysfunction in patients with TMD. Differences may be due to sampling or to diagnostic criteria for tongue dysfunction.

\begin{tabular}{|c|c|c|c|}
\hline Author & Date & Sample size & Percentage lingual dysfunction \\
\hline Gelb $^{18}$ & $1983-1985$ & 200 & $72 \%$ \\
\hline Servière $^{31}$ & 1988 & 107 & $23 \%$ \\
& 1990 & 94 & $22 \%$ \\
\hline Jeanmonod $^{19}$ & 1916 & $70 \%$ \\
\hline
\end{tabular}




\section{THE TONGUE}

The tongue body occupiesthe oral cavity and, behind the lingual $V$, the tongue base occupies the oropharynx down to the hyoid bone. The tongue comprises two muscle groups ${ }^{3}$, all innervated by the hypoglossal nerve (XII), the motor nucleus of which is organized somatotopically between protrusion and retrusion muscles ${ }^{24,25}$. The extrinsic muscles have bone insertions, and comprise: styloglossus, hyoglossus (retrusion) and genioglossus (protrusion). The intrinsic muscles (vertical, transverse, superior longitudinal and inferior longitudinal) have no bone insertion. The palatoglossus muscle of the anterior pillar of the soft palate (innervated by vagus nerve $\mathrm{X}$ ) is considered rather to be a soft palate muscle like its counterpart, the palatopharyngeal muscle (posterior soft-palate pillar). Finally, the geniohyoid and mylohyoid muscles (innervated by the trigeminal nerve $\mathrm{V}$ ) belong to the floor of the mouth, and contribute to tongue mobilization.

The tongue is mainly active in respiration, swallowing, mastication and phonation ${ }^{25}$. Lingual muscle action is also interrelated with mandibular motility and posture 24,25 , which normally involves intersegmental coordination between the motor nuclei of V, VII (facial nerve) and XII; this may be why, according to Fournier ${ }^{9}$, lingual rehabilitation contributes to recovering mandibular mobility. The pressure exerted by the tongue during swallowing is $75 \mathrm{~g} / \mathrm{cm}^{2}$ in the anterior palate and $140 \mathrm{~g} / \mathrm{cm}^{2}$ in the lateral sectors ${ }^{25}$, making the tongue essential in dento-dental and dento-maxillary balance and facial morphogenesis ${ }^{5,6,10,23}$. Over and above function, however, the habitual posture of the tongue has a continuous impact on morphogenesis ${ }^{23,30}$. When the tongue is dysfunctional, it is defective in all three functions (Chateau's "triptych" principle): position at rest, swallowing and phonation. When any one of these is impaired, the others are sure to be also.

\section{Tongue posture}

Tongue posture changes with age ${ }^{9}$, but there is no consensus on maturation age. At birth, all babies have a protruding, outspread tongue. Between 4 and 6 months, the tongue begins to withdraw, behind the dental arcades. At 6-8 months, it begins to become more vertical. Between 15 and 18 months, muscle development increases mobility within the oral cavity in all directions. according to Fournier ${ }^{9}$, by 2 years the tongue should have acquired a position with the tip on the palate, thanks to increasingly precise somesthetic contact. The age of 2 years also is that of pyramidal system motor maturity, with control of postural tonus and the beginnings of precise "idiokinetic" motricity (fine distal idiokinetic motricity is an essential element, under pyramidal system control, in contrast to the more proximal and approximate "holokinetic" motricity, which is basically under extrapyramidal control), independent movement of each limb, and inhibition of primary reflexes ${ }^{1}$. The functional tongue shows balance between agonist and antagonist muscles, retracting and curving the 
tongue, and protruding and spreading it, respectively. This balance ensures the resting position of the tongue:

- position in which tongue-base tonus is lowest;

- with apex in contact with the retroincisor buds ("contact" here meaning just touching or next to, and certainly not pushing against);

- tip of the tongue on the palate, at a postero-inferior angle toward the pharynx, thus dilating the fauces isthmus;

- when the patient's lips are gently opened and the mouth is not in maximal intercuspal occlusion, the ventral side of the tongue is visible, with a space between it and the dental arcades.

\section{Tongue functions}

\section{Swallowing $2,11,12,39$}

Swallowing is a sequential automatic function of the oral, lingual, pharyngeal, laryngeal muscles and esophagus, enabling active oral-aboral transport of solid and liquid food and saliva (upper digestive tract lubrication) to the stomach. It requires motor coordination between swallowing and respiration, and transient mechanical airway closure to prevent foreign-body inhalation. Concomitantly, soft-palate tension allows middle ear ventilation by dilating the Eustachian tube, balancing the pressures on either side of the tympanum, between middle and outer ear.

Ontogenetically, swallowing appears at the $12^{\text {th }}$ week in the fetus, whereas suction does not appear until the $24^{\text {th }}$ week. This is phylogenetically understandable, as swallowing is an ancestral function ensuring food ingestion and branchial respiration in fish, and is thus older than air respiration, which appeared only with terrestrial vertebrates (tetrapods) ${ }^{2}$. At birth, babies show the primary, immature swallowing known as suction-swallowing.

According to Fournier ${ }^{9}$, at the age of 2 years suction-swallowing should give way to secondary, mature swallowing, and if the resting position of the tongue is not established by then, it never will be spontaneously.

Swallowing has 3 stages: oral, pharyngeal and esophageal; it finishes at the cardia when the bolus passes into the stomach. The oral and pharyngeal stages overlap (isthmic stage, crossing the fauces isthmus formed by the anterior pillars of the velar palate and palatoglossus muscle), which is why the term "oropharyngeal stage" is often used; this lasts about 1 second, whereas the esophageal stage may last more than 8 seconds. The tongue is involved in the oral and pharyngeal stages $^{25}$.

Neurophysiologically, swallowing is a semiautomatic motor behaviour governed by a segmental central pattern generator in the reticular formation of the brain stem. However it can be triggered reflexively, by stimulation of Wassilieff's reflexogenic zone (tongue base and oropharynx posterior to the anterior pillars of the velar palate), or voluntarily, by the facial primary motor cortex (face M1), although only the oral stage is influenced by $\mathrm{M} 1$; this cortical regulation explains why rehabilitation of the oral stage is clinically possible. In primary, immature lingual motricity, the facial muscles (VII) predominate over the masticatory muscles $(V)$, whereas in secondary motricity it is the converse ${ }^{39}$ (fig. 1). 


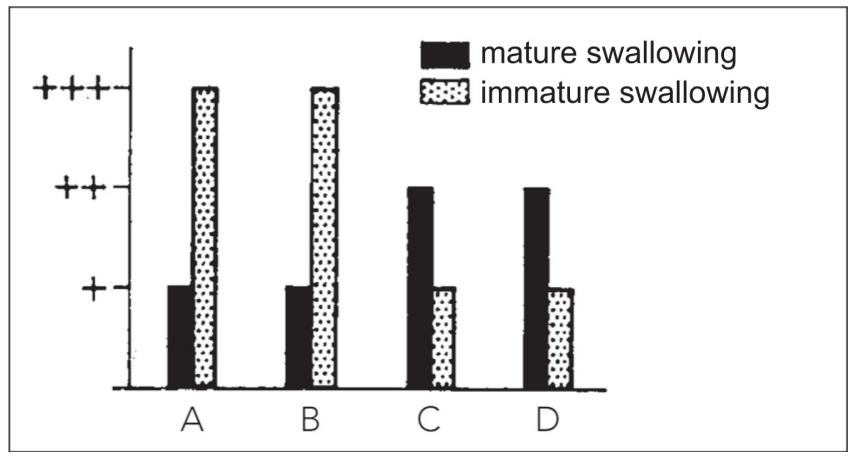

Figure 1

Comparison of primary (immature) and secondary (mature) swallowing EMG activity in (A) mental (VII), (B) oral orbicular (VII), (C) masseter (V) and (D) lateral pterygoid (V) muscles. In primary swallowing (gray), the more active muscles are innervated by VII and in secondary swallowing (black) by V. (From Graber in ref. 39).

In swallowing solid food or saliva, which happens about 1,200 times per 24-hour cycle, the mandible is blocked in maximal intercuspal occlusion, with an occlusion force of about one-tenth of maximal bite strength, while in the pause in maximal intercuspal occlusion during mastication it is about one-third. In contrast, the pause is longer (400-600 ms) in swallowing than in mastication (200 ms) (reference in ref. 12), while in swallowing liquid, the blockage in maximal intercuspal occlusion is unnecessary, and swallowing is similar to the immature function.

\section{Phonation ${ }^{4}$}

Palatal consonants ( $L, N, D$ and $T)$ : assessment criteria and thus procedures differ from therapist to therapist, due to differences in definition of palatal consonants. In French speech therapy, D and T are called "apicodental occlusive" as occlusion is achieved by applying the apex of the tongue against the superior incisors. The $L$ is an "apicodigital lateral constrictive", as the tip of the tongue may touch the superior incisors or their alveolae. In physiotherapy, palatal consonants should be produced by the tip of the tongue in contact with the retro-incisor bud without spreading the tongue.

Sibilants (S and Z): in French speech therapy, these are known as "apicodental constrictive", being produced by approaching the tip of the tongue to the incisors. In physiotherapy, the tongue is withdrawn and should not touch either the inferior or superior incisors.

Palato-alveolar fricatives: $\mathrm{SH}$ and $\mathrm{ZH}$ : the tongue does not go along the sides.

Fricatives ( $F$ and $V$ ): the inferior side of the tongue should not be bitten or go under the superior incisors.

Labial consonants (M): the superior side of the tongue descends to touch the lower lip, and both lips move simultaneously.

\section{Respiration}

The genioglossus muscle (prime tongue protruder) is essential to maintaining airway permeability, and is activated in time with the in-breath ${ }^{24,25}$. Moreover, in oral breathing, tongue posture is low and anterior ${ }^{36}$. In OSAS, tongue volume, activity and posture are also to be taken into account ${ }^{24}$. The Mallampati (tongue in protrusion) and Friedman (tongue at rest) classifications allow clinical assessment of OSAS severity (fig. 2). A meta-analysis $^{16}$ demonstrated the 


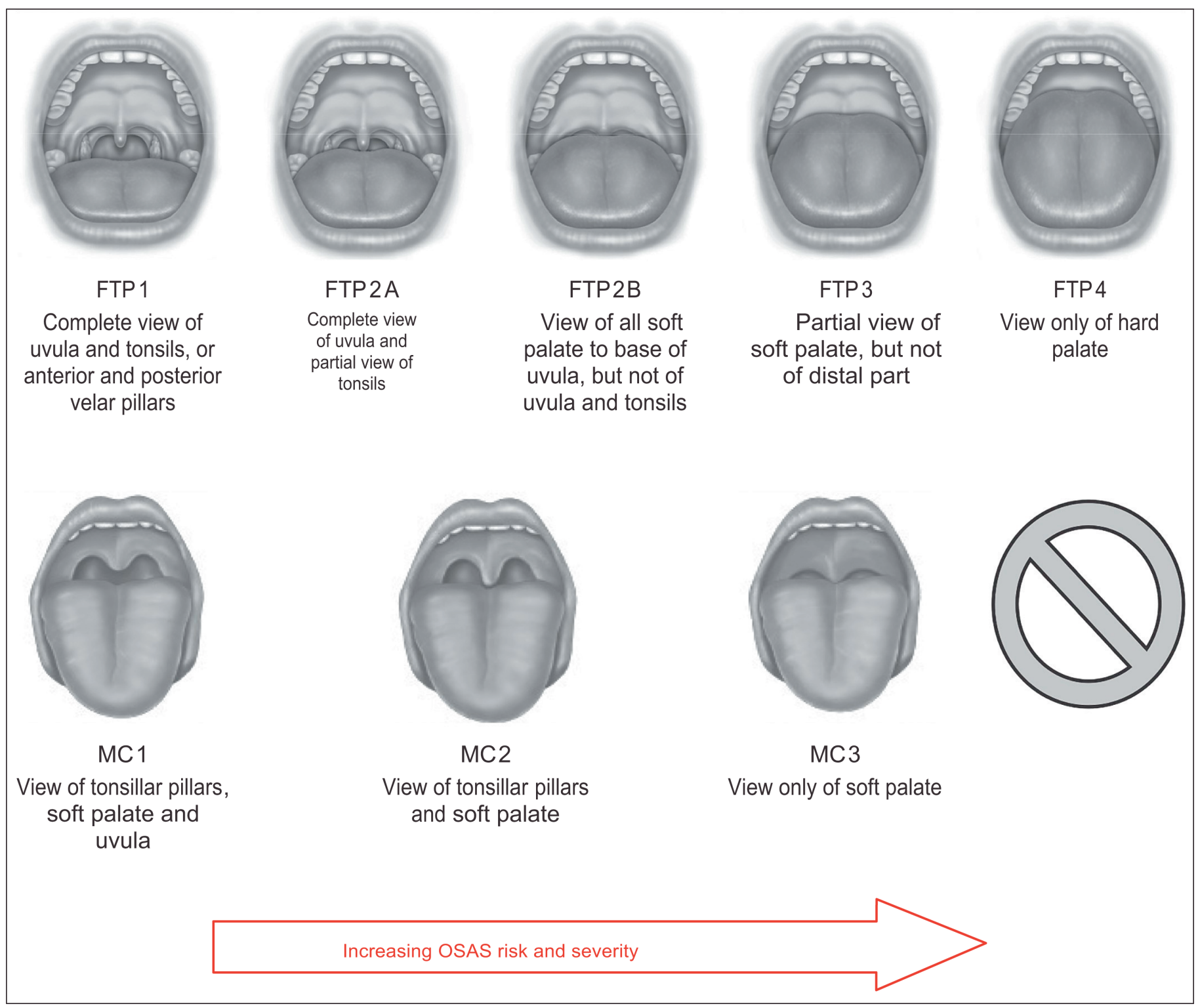

Figure 2

Comparison of tongue position at rest according to Friedman (Friedman Tongue Position, above) and tongue position in protrusion according to Mallampati (Mallampati Classification, below) in OSAS: positive correlation between tongue posture/volume and apnea/hypopnea index ${ }^{16}$.

validity of these two classifications: clinical classification of tongue posture correlates with apnea/hy- popnea index on polysomnography; the Friedman classification shows better validity than Mallampati's. 


\section{PATHOLOGIES}

\section{Dental-maxillary dysmorphism}

The tongue is involved in facial growth and morphogenesis: if it fails to achieve its normal functional position, it may induce dental-maxillary dysmorphism $^{8}$. The pressure of the tongue on the dental arcades may jeopardize orthodontic treatment. In some cases, it may even detach the contention mechanism. The tongue plays an essential part in dento-dental and dento-maxillary balance ${ }^{8,23}$ and may induce dysmorphism or, conversely, its behavior may result from adaptation to dysmorphism. The tongue reaches almost its definitive size around the age of 8 years, but in some cases continues to grow in adulthood ${ }^{32}$.

\section{Respiratory disorder}

A badly positioned tongue can form an obstacle to naso-nasal breathing (in and out both through the nose), inducing oral breathing - unless, conversely, oral breathing leads to tongue malpositioning. This may correlate with reduced oral cavity and sinus permeability, stagnation of secretion, iterative ENT infection (rhinopharyngitis, otitis, etc.), or impaired middleear ventilation due to Eustachian tube dysfunction, inducing hearing loss.

\section{Temporomandibular disorder pain}

Masticatory apparatus pain according to Lund's pain-adaptation model ${ }^{13,26,27}$, involves paradoxical masticatory muscle activity: antagonist hypoactivity on closure laccounting for masticatory impotence and reduced bite force) and weak antagonist activity on opening (accounting for reduced jaw opening). In TMD pain, the prevalence of tongue dysfunction is elevated $18,19,31$ (Table I). The weak agonistic activity of the masticatory muscles $(\mathrm{V})$, due to persistent or chronic musculoskeletal pain, might also induce primary lingual motricity whereby facial muscle activity (VII) compensate weak masticatory muscle (V) agonistic hypoactivity $^{13}$. Conversely, immature tongue posture and function might be one of the risk factors for masticatory dysfunction. These hypotheses require investigation.

\section{Parafunction: bruxism and associated comorbidities}

Lund $^{27}$ distinguished 3 categories of patient: (i) bruxism with TMD, (ii) bruxism without $T M D$, and (iii) TMD without bruxism. In TMD, however, the prevalence of bruxism is greater than in patients without TMD. According to Lund, the higher prevalence of bruxism (muscle hyperactivity) in TMD has led to confusion between the two, with muscle pain being attributed to hyperactivity (on Travell's $\mathrm{s}^{38}$ old vicious-circle theory). However, the two are not to be confused, even if bruxism is doubtless a risk factor for pain in TMD, although we do not really know why or how bruxism causes or maintains TMD in some patients but not others ${ }^{33}$. Normal sleep shows rhythmic masticatory muscle activity (RMMA), which is 3-fold more frequent in sleep bruxism: moreover, 
RMMA displays elevator/depressor co-contraction, enhancing airway permeability 22

In OSAS, sleep bruxism may be a compensatory phenomenon in respiration, explaining their frequent association ${ }^{28}$. It was also recently sug- gested that there are interrelations between bruxism and lingual dysfunction ${ }^{21}$, unless indeed respiratory disorder is the common denominator of bruxism and lingual dysfunction but these hypotheses remain to be explored.

\section{LINGUAL ASSESSMENT ACCORDING TO DIFFERENT THERAPISTS}

There are basically 3 professions practicing tongue rehabilitation: speech therapists, hygienists (dental assistants, in the US and Canada), and physiotherapists. It is interesting to compare their respective approaches, with their differences and common points.

\section{Speech-therapy assessment}

\section{Lingual function}

- Resting position of apex.

- Form and aspect of tongue (signs of occlusion, bites, etc.).

- Short frenum.

- Voluntary tongue movement (elevation, retraction, lateral deviation, protrusion, etc.).

- Lingual support (with or without masseter contraction, dento-dental contact, lip involvement).

\section{Velar function}

- Tonicity.

- Nausea reflex.

- Pharyngeal adenoids.

- Uvula aspect.

- Nasal loss or isthmic incompetence.

\section{Mandibular mobility}

- Mandibular elevator/depressor tonicity.

- Mastication analysis.

\section{Speech articulation and phonation}

- Articulation of apicoalveolar consonants.

- Articulation of sibilants and palatoalveolar fricatives.

- Sigmatism (lisp).

- Voice quality.

- Pharyngeal mobility.

- Fatigue on prolonged phonation.

\section{Respiration}

- Exclusive or mixed oral respiration.

- Nocturnal drooling.

- Snoring (rhonchopathy).

- ENT pathology.

- Ongoing treatments.

- Inverted nostril reflex: ala opening on outbreath and closure on inbreath.

- Respiratory mode (thoracic or thoraco-abdominal).

\section{Assessment by hygienists (Garliner method) ${ }^{17}$}

- Does the patient have chronic headache?

- Does the patient have the mouth open?

- Have the teeth moved after DFO treatment?

- Is there a dental gap?

- Does the patient complain of TMD pain or neck pain? 
- Is the tongue still in the same position after treatment?

- Is the tongue bent (tooth pressure)?

- Particular oral habits (thumb/finger sucking, nail biting)?

- Does the tongue touch the teeth in pronouncing " $\mathrm{S}$ "?

- Does the tongue pass between the teeth on swallowing?

- If the patient is an oral breather, is there gingivitis?

- Does the patient grit his/her teeth?

- Does the patient show chronic stomach pain, eructation, drooling, hiccough?

- Does the patient have the head leaning forward?

\section{Physiotherapy assessment (Fournier method) ${ }^{9}$}

The clinical assessment follows detailed history-taking (fig. 3).

\section{Tongue}

- Resting position

- Good position: apex in contact with retro-incisor buds.

- Bad positions: between teeth or lips (vertical gap, fig. 4), against palatal side of maxillary incisors (class II1 malocclusion), tip against lingual side of mandibular incisors with back on palate (class 112 malocclusion), low (class III malocclusion, fig. 5), or laterally interposed. In class II 1 withsevereoverhangorclass II2 with overlap, tongue position is not visible, and phonetic tests are necessary to assess lingual dyspraxia.

- Indentation of tongue edges

- Yes/no (fig. 6).

- Frenum

- Length normal if interincisor distance on maximal opening is at least 3 finger-widths, with apex on palate.

- The frenum is too short if the tongue cannot touch the palate in maximum oral opening. In open mouth, the maximum inter-incisor distance at which the tip of the tongue remains in contact with the palate is measured (fig. 7). If the frenum is too short, the tongue may fork.

- Abnormal swallowing

Excessive facial muscle contraction: oral orbicular and modiolus contraction, labiomental groove tension, cheek aspiration (visible or not) (fig. 8).

- Phonation (in French)

- Palatals (L, N, D, T): pronounce "DINETTE" and "TARTINE" (the most informative test).

- Sibilants (S, Z): pronounce "SAUCISSON".

- Palato-alveolar fricatives $(\mathrm{SH}, \mathrm{ZH})$ : pronounce "CHAT" and "JEU".

- Fricatives ( $F, V)$ : pronounce "FEU" and "VCEUX".

- Labials (M): say "MAMAMAMA".

\section{Lips}

- Upper or lower lip tonus: tonic, atonic (fig. 7) or stretched like a belt.

\section{Buccinators}

- Balanced, fatigable or asymmetric.

\section{Masticatory apparatus and temporomandibular joints}

- Deviation of centers:

- yes/no (rightward/leftward).

- Pain:

- yes/no.

- Snap or crepitation:

- yes/no.

- Mastication:

- strictly unilateral or alternating left/right; 


\section{BILAN LINGUAL}

\section{POSITION DE REPOS DE LA LANGUE}

1. Langue entre les arcades ou langue entre les lèvres
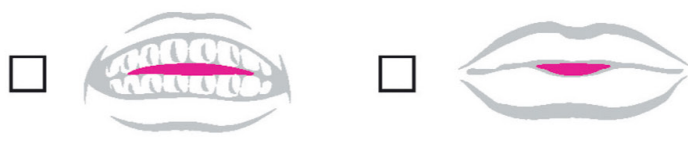

2. Langue en appui sur le bloc incisivo-canin maxillaire

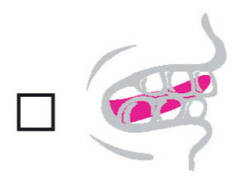

3. Dos de la langue au palais et pointe sur les racines des incisives mandibulaires

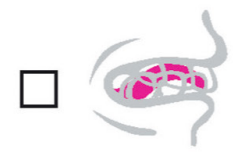

4. Langue basse

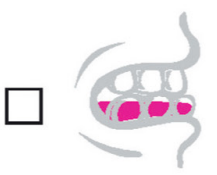

\section{DÉGLUTITION}

1. Zone péri-buccale

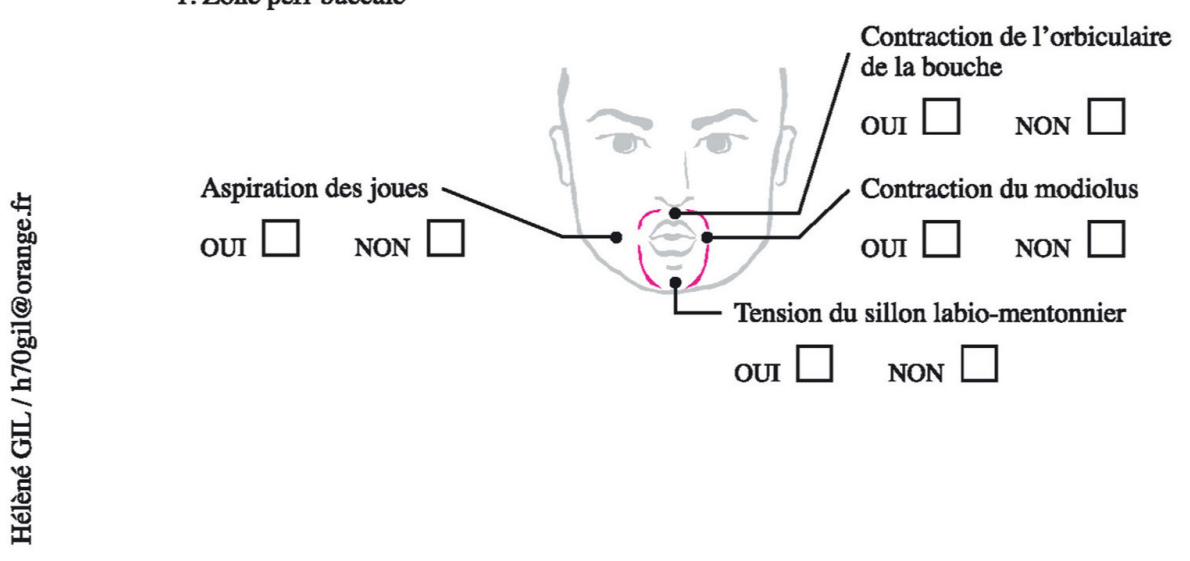

Figure 3

Clinical tongue posture/function assessment form. (Page 1) 
2. Mouvement de la langue en bouche Interposition linguale OUI $\square$ NON

\section{PHONATION}

Test des palatales

- Épeler DINETTE et TARTINE :

La langue touche le bloc incisivo-canin

OUI $\square$ NON

\section{VENTILATION}

1. Le matin, avez-vous la bouche sèche?

Respiration buccale nocturne

OUI $\square$ NON $\square$

2. Avez-vous de façon récurrente des problèmes ORL?

OUI

NON (rhino-pharyngite, otites, ronflements, SAOS...)

\section{PARAFONCTIONS}

1. Portez-vous vos doigts ou des objets en bouche (pouce, doigts, lèvre...) ?

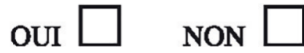

2. Sentez-vous votre langue affleurer de façon répétitive vos dents et vos lèvres ? (tétage de langue)

3. Sentez-vous un contact entre vos dents?

OUI $\square$ NON

穿

4. Grincez-vous des dents?

OUI

NON

Figure 3

Clinical tongue posture/function assessment form. (Page 2) 


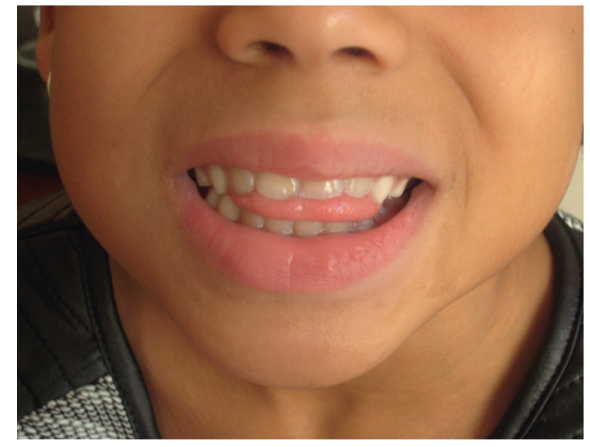

Figure 4

Lingual interposition between teeth in malocclusion with anterior gap.

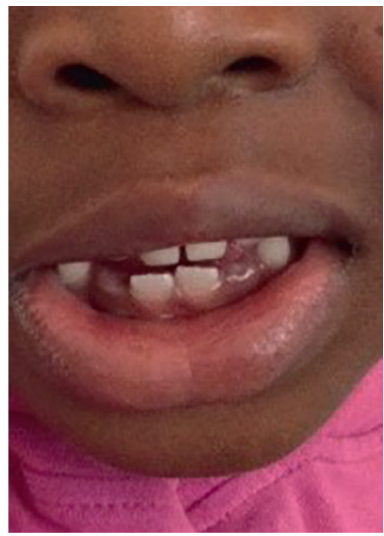

Figure 5

Low tongue in class III malocclusion.

- difficulty chewing hard and thick food.

- Limited mandibular movement:

- yes/no.

- Mandibular mobility

- oral opening/closure: supple/stiff, deflected (rightward/leftward) or deviated ("bayonet" movement) ;

- mandibular protrusion: supple/stiff, rightward/leftward asymmetry, or uncoordinated because not understood by patient;

- mandibular laterality: supple/stiff, or uncoordinated because not understood.

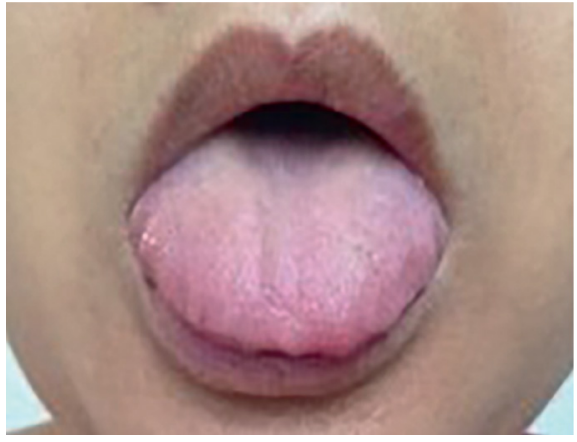

Figure 6

Tongue edge indentations.

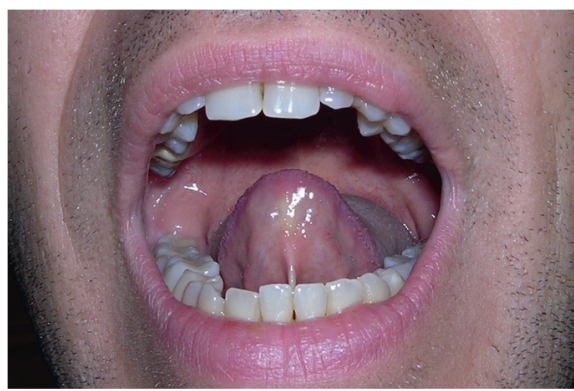

Figure 7

Short frenum: tip of tongue cannot touch palate with mandible lowered.

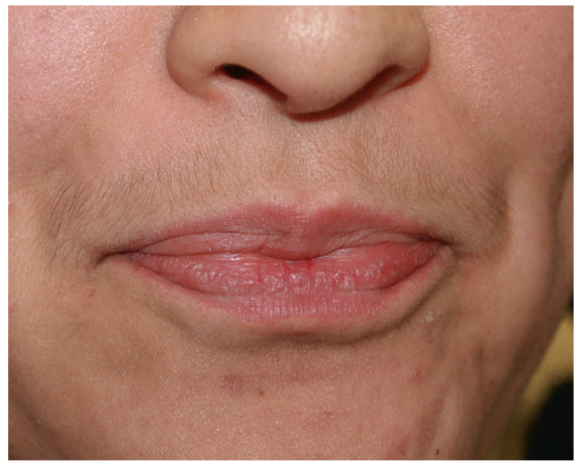

Figure 8

Excessive facial muscle contraction in oral swallowing phase.

\section{Respiration}

- oral/nasal.

- ENT pathology: 
- yes/no: rhinopharyngitis, otitis, rhonchopathy, OSAS, pharyngitis and sinusitis;

- Rosenthal test: patient breathes 15 times by the nose. Pulse is monitored. Test negative if mouth remains closed, patient not breathless, no bother or pulse acceleration; positive if mouth opens, slight perspiration above upper lip, pulse acceleration or elevation of first ribs under accessory inspiratory muscle action. Degree of positivity is recorded

\section{Bad habits}

- Interposition (fingers, tongue, lips, pencils).

- Onychophagia.

- Waking and/or sleep bruxism, centered and/or excentric.

\section{Posture (frontal and lateral)}

- Head in relation to neck.

- Spinal curves.

- Pelvic position: anteversion/retroversion.

- Plantar weight-bearing.

- Step process.

\section{Ocular convergence}

- Normal/deficient.

\section{Psychological and psychosomatic tension (for relaxation)}

- Sleep quality: good/poor (difficulty going to sleep, insomnia).

- Muscle pain.

- Organic disorders: heart rhythm, respiration, digestion, gynecological, etc.

- Nausea and vomiting.

- Headache: location.

\section{DIAGNOSTIC CRITERIA FOR DYSFUNCTIONS AND PARAFUNCTIONS}

The present summary assessment is intended for prescribers (see fig. 3, "Clinical form").

\section{Resting position of tongue}

Open the patient's lips slightly, after warning.

- Patients tend to show labial interocclusion. the tongue is visible between teeth/lips. Anterior or lateral dental gap with the tongue in the gap (see fig. $3, N^{\circ} 1$ ).

- Tongue in interdental diastemas. It touches the lingual side of the maxillary incisor-canine sector. In large anteroposterior shift with maxillary overhang, the tongue may not be visible (class II1); palatal test then indicates defective positioning (Chateau's triptych principle) (see fig. 3, $N^{\circ} 2$ ).

- Position encountered sometimes in class II2, with supra-occlusion. The tongue is completely invisible. Palatal test (inducing wide oral opening and better visibility) indicates lingual dyspraxia (see fig. $3, N^{\circ} 3$ ).

- Tongue spread, resting on oral floor: class III (see fig. 3, $N^{\circ} 4$ ).

\section{Swallowing}

- Ask the patient to swallow once; check peri-oral region carefully for excessive platysma contraction compensating masticatory hypoactivity: 
- oral orbicular muscle contraction ("kissing" gesture);

- modiolus contraction (dimples at lip commissure);

- labiomental groove tension (area under lower lip tenses);

- more or less visible cheek aspiration; if not visible, ask if patient feels slight cheek aspiration on swallowing saliva.

- Ask the patient to swallow again, and gently open lips to see the movement of the tongue in the mouth. If nothing is visible, especially if no labiojugal muscle involvement, palatal test indicates abnormal swallowing.

\section{Phonation}

The "DINETTE / TARTINE" palatal test optimally diagnoses lingual dyspraxia, with larger opening and better tongue visibility. When there is no dysfunction, the apex touches the retro-incisor buds on pronouncing $L$, $\mathrm{N}, \mathrm{D}$ and $\mathrm{T}$. In dyspraxia, the tongue protrudes. The test also contributes to the patient's awareness, encouraging rehabilitation.

$$
t=0
$$

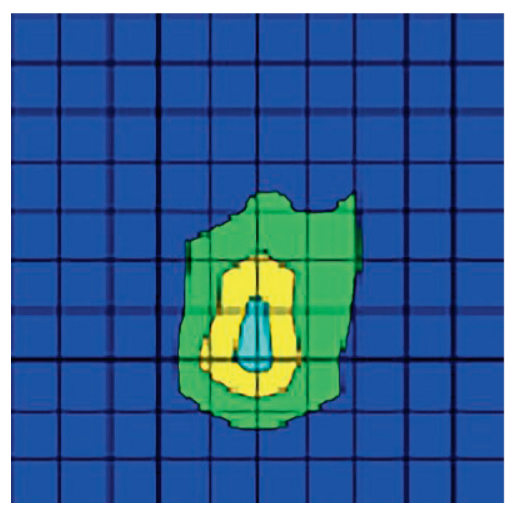

\section{Respiration}

It is not just because the patient has the mouth closed and breathes nasally during the day that the same is true at night. Ask: "In the morning, when you wake up, is your mouth dry; do you have a drink during the night; do you have chapped lips?" If the answer is "yes", there is nocturnal oral respiration and a problem that needs correcting. If the disorder is severe, there may be pinching of the nasal alae on the inbreath. If there is ENT pathology, the tongue must be malpositioned, with oral respiration.

\section{Parafunctions}

For bad habits, it is useful to ask the same questions at the next appointment. Patients are not immediately aware of their habits, and assessment can enable the practitioner to:

- detect lingual dyspraxia;

- advise about treatment;

- suggest neuromuscular rehabilitation with prostheses;

- prescribe maxillofacial rehabilitation.

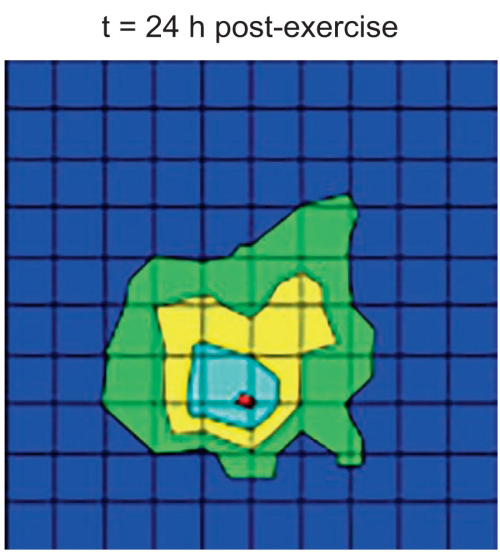

Figure 9

1 hour's protrusion exercise extends the size of the tongue primary motor cortex (M1) and enhances tongue muscle cortico-bulbar motoneuron excitability ${ }^{35}$. 


\section{WHEN TO PRESCRIBE?}

It seems that the greater the number of disorders detected on assessment, the more important it is to initiate rehabilitation early. This is especially true when disorder is associated with parafunction. However, rehabilitation is always difficult when the patient is bearing orthodontic apparatuses (palatal plate, screw-jack plate, quadhelix, etc.). Apart from

\section{CONCLUSION}

At the end of maxillofacial rehabilitation, Chateau triptych (resting position, swallowing and phonation) corrections should become reflex: otherwise, there is risk of recurrence. Likewise, all associated problems have to be solved: lip tonus, naso-nasal respiration at rest and under effort, relaxation of tense muscles, bruxism, and posture.

Alongside relaxation, the clinical effects of maxillofacial and lingual rehabilitation are many: masticatory and cervical muscle pain relief, reduced incidence of bruxism and, with associated orthodontic treatment, correction of dentomaxillary dysmorphism due to poor tongue posture. Bruxism may recur, but the patient no longer tolerates it and now has the means to stop it completely.

Recent clinical studies demonstrated the biological effects of physiotherapy in musculoskeletal disorders (non-specific low back and neck pain) and suggested hypotheses $^{14}$. Likewise, pioneering studies showed that tongue exercises in- crowding, tongue/palate exteroception is vitiated, preventing correction becoming reflex. For some prescribers, the problem is finding a nearby rehabilitation practitioner, and motivating the patient: not all cases require such active rehabilitation: some will respond to a nocturnal lingual envelope, functional rehabilitation, etc.

duced neuroplastic modifications in the primary motor cortex (M1) of the lingual muscles, increasing corticobulbar motoneuron excitability and the size of the lingual muscle motor area (fig. 9) 7,34,35. (The corticobulbar motoneurons of the cranial nerve motor system constitute the corticobulbar bundle, previously known as the geniculate bundle, which is the counterpart of the pyramidal bundle of the spinal motor system. The corticobulbar motoneurons connect to the cranial nerve motoneurons, and the corticospinal motoneurons to the ventral (motor) horn of the spinal cord. Both ventral spinal horn and cranial motor nuclei form the origin of the $\alpha$ motoneurons commanding the muscle fibers ${ }^{11}$.) Thus, better knowledge of these biological effects should help rationalize maxillofacial rehabilitation as a whole and lingual rehabilitation in particular.

Conflict of interest: The authors declare no conflicts of interest. 


\section{REFERENCES}

1. Amielle-Tison C. Démarche clinique en neurologie du développement. Paris: Masson, 2008:29-43.

2. Azerad J. Physiologie de la manducation. Paris: Masson, 1992:37-53.

3. Baker EW. Anatomie tête et cou en odontostomatologie. Baker EW. Paris: Lavoisier Médecine Sciences, 2012:204-213.

4. Bondy L. Éléments de phonétique. Paris: J.B. Baillière, 1977:35-45.

5. Bonnet B. In Chateau M. Orthopédie dento-faciale, tome 2. Paris: Édition CdP, 1993:248-252.

6. Bonnet B. Un appareil de reposturation : I'enveloppe linguale nocturne (ELN). Rev Orthop Dento Faciale 1992;26:329-347.

7. Boudreau S, Romaniello A, Wang K, Svensson P, Sessle BJ, Arend-Nielsen L. The effects of intra-oral pain on motor cortex neuroplasticity associated with short-term novel tongue-protrusion training in humans. Pain 2007;132:169-178.

8. Chateau M. Orthopédie dento-faciale, tome 2, Clinique. Paris: Édition CdP, 1993:25-26.

9. Chauvois A, Fournier M, Girardin F. Rééducation des fonctions dans la thérapeutique orthodontique. Paris: Édition SID, 1991:77-78.

10. Couly G, Gitton Y. Développement céphalique. Embryologie, génétique, croissance et pathologie. Rueil-Malmaison: Édition CdP, 2012:105-106.

11. Fougeront N, Garnier B, Fleiter B. Motricité, fonctions manducatrices et réflexes de la mâchoire (1 ${ }^{\text {re }}$ partie). Med Buccale Chir Buccale 2014;20:161-170.

12. Fougeront N, Garnier B, Fleiter B. Automatismes de I'appareil manducateur et fonctions cervicales connexes (2e partie). Med Buccale Chir Buccale 2014;20:253-262.

13. Fougeront N, Garnier B, Fleiter B. Dysfonctionnements musculaires douloureux de I'appareil manducateur et dysfonctionnements cervicaux et linguaux connexes ( $3^{\mathrm{e}}$ partie). Med Buccale Chir Buccale 2015 DOI: 10.1051/mbcb/2014022.

14. Fougeront N, Garnier B, Fleiter B. Rééducation fonctionnelle des troubles musculosquelettiques de l'appareil manducateur : de ses principes biologiques à la clinique (4e partie). Med Buccale Chir Buccale 2015 DOI: 10.1051/mbcb/2014034.

15. Franco AL, Gonçalves DAG, Castanharo SM, Speciali JG, Bigal ME, Camparis CM. Migraine is the most prevalent primary headache in individuals with temporomandibular disorders. J Orofac Pain 2010;24:287-292.

16. Friedman M, Hamilton C, Samuelson CG, Lundgren ME, Pott T. Diagnostic value of the Friedman Tongue Position and Mallampati Classification for obstructive sleep apnea: a meta-analysis. Otolaryngol Head Neck Surg 2013;148:540-547.

17. Garliner D. Myofunctional Therapy in Dental Practice. Brooklyn: Bartel Dental Book Co, 2nd ed, 1974.

18. Gelb H, Bernstein I. Clinical evaluation of two hundred patients with temporomandibular joint syndrome. J Prosth Dent 1983;49:234-243.

19. Jeanmonod A. La responsabilité de la déglutition dysfonctionnelle dans l'apparition des dysfonctions de l'appareil manducateur. Rapport de l'Académie Nationale de Chirurgie Dentaire, 1990.

20. Jeanmonod A. Occlusodontologie, applications cliniques. Paris : Éditions CdP, 1988.

21. Launay $Y$, Zitouni N. Le bruxisme est-il une complication de la déglutition atypique ? Actualités Odontostomatologiques 2014;269:22-26.

22. Lavigne GJ, Kato T, Kolta A, Sessle BJ. Neurobiological mechanism involved in sleep bruxism. Crit Rev Oral Biol Med 2003;14:30-46.

23. Lejoyeux E. Flageul F. Orthopédie dento-faciale. Une approche bioprogressive. Paris: Quintessence International, 1999. 
24. Lowe AA. Neural control of tongue posture. In: Taylor A. Neurophysiology of the Jaws and Teeth. London: Macmillan Press, 1990:322-368.

25. Lowe AA. The neural regulation of tongue movements. Prog Neurobiol 1981;15:295344.

26. Lund JP, Donga R, Widmer CG, Stohler CS. The pain-adaptation model: a discussion of the relationship between chronic musculoskeletal pain and motor activity. Can J Physiol Pharmacol 1991;69:683-694.

27. Lund JP, Widmer CG, Schwartz G. What is the link between myofascial pain and dysfunction? In: van Steenbergh D and De Laat A (ed). Electromyography of Jaw Reflexes in Man (proceedings of the IADR). Leuven : Leuven University Press, 1989:427-444.

28. Prime I. Prendre en charge le syndrome d'apnée-hypopnées obstructives du sommeil en odontologie. Clinic 2012;33:119-125.

29. Rozencweig D. Algies et dysfonctionnements de l'ap- pareil manducateur. Paris: Édition CdP, 1994:253-270.

30. Salvadori A. La récidive. Orthod Fr 1999;70:32.

31. Servière F. Dysfonctions linguales et syndrome algo-dysfonctionnel de l'appareil manducateur. Inf Dent 1988;70:1211-1217.

32. Sperber GH. Craniofacial embryology. Dental practio- ner handbook, 15. London: Wright, 4th Ed., 1989:179- 187.

33. Svensson P, Jadidi F, Arima T, Baad-Hansen L, Sessle BJ. Relationships between craniofacial pain and bruxism. J Oral Rehab 2008;35:524:547.

34. Svensson P, Romaniello A, Arendt-Nielsen L, Sessle BJ. Plasticity in corticomotor control of the human tongue musculature induced by tongue-task training. Exp Brain Res 2003;152:42-51.

35. Svensson P, Romaniello A, Wang K, Arendt-Nielsen L, Sessle BJ. One hour of tonguetask training is associated with plasticity in corticomotor control of the human tongue musculature. Exp Brain Res 2006;173:165-173.

36. Talmant J, Deniaud J, Nivet MH. Mécanismes posturaux. Orthod Fr 2003;74:227-283.

37. Tavernier $L, C h o b a u t ~ J C$. Rééducation tubaire : indications techniques et résultats. Fr ORL 2006;91:241-248.

38. Travell JG, Simons DG. Myofascial pain and dysfunction, the trigger point manual. Baltimore : Williams and Wilkins, 1983.

39.. Woda A, Fontenelle A. Physiologie de I'appareil manducateur. In. Chateau M. Orthopédie dento-faciale, tome 1. Paris: Édition CdP, 1993:167-229 et 219-220. 